Acta Crystallographica Section D

Biological

Crystallography

ISSN 0907-4449

\section{addenda and errata}

Structural and functional studies of ReP1NCXSQ, a protein regulating the squid nerve $\mathrm{Na}^{+} / \mathrm{Ca}^{2+}$. Erratum

\section{Alexandra Cousido-Siah, ${ }^{a}$ Daniel Ayoub, ${ }^{\text {b,c }}$ Graciela Berberián, d Mariana Bollo, d Alain Van Dorsselaer, François Debaene, ${ }^{b, c}$ Reinaldo DiPolo, ${ }^{\text {e Tatiana Petrova, }}{ }^{f}$ Clemens Schulze-Briese, ${ }^{g}$ Vincent Olieric, ${ }^{g}$ Adriana Esteves, ${ }^{h}$ André Mitschler, ${ }^{a}$ Sarah Sanglier-Cianférani, Luis Beaugéd $^{d}$ and Alberto Podjarny ${ }^{\mathrm{a} *}$}

a Department of Structural Biology and Genomics, IGBMC, CNRS, INSERM, Université de Strasbourg, Illkirch, France, ${ }^{\mathbf{b}}$ Laboratoire de Spectrométrie de Masse BioOrganique (LSMBO), Université de Strasbourg, IPHC, 25 Rue Becquerel, 67087 Strasbourg, France, 'CNRS, UMR7178, 67037 Strasbourg, France, 'dLaboratorio de Biofísica, Instituto de Investigación Médica 'Mercedes y Martín Ferreyra' (INIMECCONICET), Córdoba, Argentina, ${ }^{\mathbf{e} C e n t r o ~ d e ~ B i o f i ́ s i c a ~ y ~ B i o q u i ́ m i c a, ~ I n s t i t u t o ~}$ Venezolano de Investigaciones Científicas, Caracas, Venezuela, 'Institute of Mathematical Problems of Biology, Russian Academy of Sciences, Pushchino
142290, Russian Federation, ${ }^{\mathbf{g}}$ SLS, PSI, Villigen, Switzerland, and ${ }^{\mathbf{h}}$ Sección Bioquímica, Facultad de Ciencias, UdelaR, Montevideo, Uruguay

Correspondence e-mail: podjarny@igbmc.fr

A correction is published to Table 2 in the article by CousidoSiah et al. [(2012), Acta Cryst. D68, 1098-1107].

On page 1103 of the article by Cousido-Siah et al. (2012) the decimal points are missing in the molecular masses given in Table 2. The correct masses are included in the corrected Table 2 given below. The conclusions of the article remain unchanged.

\section{References}

Cousido-Siah, A., Ayoub, D., Berberián, G., Bollo, M., Van Dorsselaer, A., Debaene, F., DiPolo, R., Petrova, T., Schulze-Briese, C., Olieric, V., Esteves, A., Mitschler, A., Sanglier-Cianférani, S., Beaugé, L. \& Podjarny, A. (2012). Acta Cryst. D68, 1098-1107.

Table 2

Summary of identified fatty acids from HRMS measurements (Fig. 3).

Theoretical molecular masses are indicated as $[M-\mathrm{H}]^{-}$ions. n.i., not identified.

\begin{tabular}{|c|c|c|c|c|}
\hline Peak No. & Fatty acid & $\begin{array}{l}\text { Molecular } \\
\text { formula }\end{array}$ & $\begin{array}{l}\text { Theoretical } \\
\text { monoisotopic } \\
\text { mass (Da) }\end{array}$ & $\begin{array}{l}\text { Measured } \\
\text { monoisotopic } \\
\text { mass (Da) }\end{array}$ \\
\hline 1 & Docosahexaenoic acid (DHA) & $\mathrm{C}_{22} \mathrm{H}_{32} \mathrm{O}_{2}$ & 327.232 & $327.232(4)$ \\
\hline 2 & Palmitoleic acid & $\mathrm{C}_{16} \mathrm{H}_{30} \mathrm{O}_{2}$ & 253.216 & $253.215(4)$ \\
\hline 4 & Dihomo- $\gamma$-linoleic acid (DGLA) & $\mathrm{C}_{20} \mathrm{H}_{34} \mathrm{O}_{2}$ & 305.248 & $305.247(1)$ \\
\hline & or eicosatetraenoic acid (ETA) + n.i. & & n.i. & $267.232(3)$ \\
\hline 5 & Palmitic acid & $\mathrm{C}_{16} \mathrm{H}_{32} \mathrm{O}_{2}$ & 255.232 & 255.232 \\
\hline 6 & Oleic acid & $\mathrm{C}_{18} \mathrm{H}_{34} \mathrm{O}_{2}$ & 281.248 & $281.247(4)$ \\
\hline
\end{tabular}


Acta Crystallographica Section D

Biological

Crystallography

ISSN 0907-4449

\section{Structural and functional studies of ReP1-NCXSQ, a protein regulating the squid nerve $\mathrm{Na}^{+} / \mathrm{Ca}^{2+}$ exchanger}

\begin{abstract}
Alexandra Cousido-Siah, ${ }^{a}$ Daniel Ayoub, ${ }^{b, c}$ Graciela Berberián, ${ }^{d}$ Mariana Bollo, ${ }^{\text {d }}$ Alain Van Dorsselaer, ${ }^{b, c}$ François Debaene, ${ }^{b, c}$ Reinaldo DiPolo, ${ }^{e}$ Tatiana Petrova, ${ }^{f}$ Clemens Schulze-Briese, ${ }^{\mathrm{g}}$ Vincent Olieric, ${ }^{\mathrm{g}}$ Adriana Esteves, ${ }^{\mathrm{h}}$ André Mitschler, ${ }^{\text {a }}$ Sarah SanglierCianférani, ${ }^{\text {b,c }}$ Luis Beaugé ${ }^{\mathrm{d}}$ and Alberto Podjarny ${ }^{a}$.
\end{abstract}

a Department of Structural Biology and Genomics, IGBMC, CNRS, INSERM, Université de Strasbourg, Illkirch, France, 'baboratoire de Spectrométrie de Masse BioOrganique (LSMBO), Université de Strasbourg, IPHC, 25 Rue Becquerel, 67087 Strasbourg, France, 'CNRS, UMR7178, 67037 Strasbourg, France,

${ }^{\mathbf{d}}$ Laboratorio de Biofísica, Instituto de Investigación Médica 'Mercedes y Martín Ferreyra' (INIMEC-CONICET), Córdoba, Argentina, ${ }^{\mathbf{e}}$ Centro de Biofísica y Bioquímica, Instituto Venezolano de Investigaciones Científicas, Caracas, Venezuela, Institute of Mathematical Problems of Biology, Russian Academy of Sciences, Pushchino 142290,

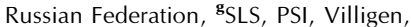
Switzerland, and $\mathbf{h}_{\text {Sección Bioquímica, Facultad }}$ de Ciencias, UdelaR, Montevideo, Uruguay

Correspondence e-mail: podjarny@igbmc.fr
The protein ReP1-NCXSQ was isolated from the cytosol of squid nerves and has been shown to be required for MgATP stimulation of the squid nerve $\mathrm{Na}^{+} / \mathrm{Ca}^{2+}$ exchanger NCXSQ1. In order to determine its mode of action and the corresponding biologically active ligand, sequence analysis, crystal structures and mass-spectrometric studies of this protein and its Tyr128Phe mutant are reported. Sequence analysis suggests that it belongs to the CRABP family in the FABP superfamily. The X-ray structure at $1.28 \AA$ resolution shows the FABP $\beta$-barrel fold, with a fatty acid inside the barrel that makes a relatively short hydrogen bond to Tyr128 and shows a double bond between $\mathrm{C} 9$ and $\mathrm{C} 10$ but that is disordered beyond C12. Mass-spectrometric studies identified this fatty acid as palmitoleic acid, confirming the double bond between $\mathrm{C} 9$ and C10 and establishing a length of $16 \mathrm{C}$ atoms in the aliphatic chain. This acid was caught inside during the culture in Escherichia coli and therefore is not necessarily linked to the biological activity. The Tyr128Phe mutant was unable to activate the $\mathrm{Na}^{+} / \mathrm{Ca}^{2+}$ exchanger and the corresponding crystal structure showed that without the hydrogen bond to Tyr128 the palmitoleic acid inside the barrel becomes disordered. Native mass-spectrometric analysis confirmed a lower occupancy of the fatty acid in the Tyr128Phe mutant. The correlation between (i) the lack of activity of the Tyr128Phe mutant, (ii) the lower occupancy/disorder of the bound palmitoleic acid and (iii) the mass-spectrometric studies of ReP1-NCXSQ suggests that the transport of a fatty acid is involved in regulation of the NCXSQ1 exchanger, providing a novel insight into the mechanism of its regulation. In order to identify the biologically active ligand, additional highresolution mass-spectrometric studies of the ligands bound to ReP1-NCXSQ were performed after incubation with squid nerve vesicles both with and without MgATP. These studies clearly identified palmitic acid as the fatty acid involved in regulation of the $\mathrm{Na}^{+} / \mathrm{Ca}^{2+}$ exchanger from squid nerve.
Received 8 February 2012

Accepted 8 May 2012

PDB References: ReP1-NCXSQ, 3ppt; Tyr128Phe mutant, 3pp6.

\section{Introduction}

$\mathrm{Na}^{+} / \mathrm{Ca}^{2+}$ exchangers are highly regulated by processes taking place at the large intracellular loop. The two exchangers that have been most studied functionally and structurally are those 
from mammalian heart $\left(\mathrm{NCX}^{\mathbf{1}}\right)$ and squid nerve (NCXSQ1) (Blaustein \& Lederer, 1999; DiPolo \& Beaugé, 2006). Both were studied in their native state in situ (giant patch clamp, internally dialyzed squid giant axons or inside-out plasma membrane vesicles) or in alien cells expressing the cloned exchangers (Berberián et al., 2012). The basis of these regulations are related to the existence of nontransporting $\mathrm{Ca}^{2+}$ regulatory sites located on the intracellular 'regulatory' loop; these sites must be occupied in order for any transport mode to take place. Ionic $\left(\mathrm{H}_{\mathrm{i}}^{+}\right.$and $\left.\mathrm{H}_{\mathrm{i}}^{+}+\mathrm{Na}_{\mathrm{i}}^{+}\right)$inhibition acts by impairing the binding of $\mathrm{Ca}^{2+}$ to those sites located in two domains named CBD1 and CBD2 (Hilge et al., 2006; Nicoll et al., 2006); as expected, their effects are counteracted by increasing the concentration of intracellular calcium $\left[\mathrm{Ca}^{2+}\right]_{i}$. In addition, there is an MgATP up-regulation which, by an as yet unknown intimate mechanism, protects the $\mathrm{Ca}^{2+}$-regulatory site from intracellular $\mathrm{H}_{\mathrm{i}}^{+}$and $\mathrm{H}_{\mathrm{i}}^{+}+\mathrm{Na}_{\mathrm{i}}^{+}$inhibition (Doering \& Lederer, 1994; Hilgemann et al., 1992; DiPolo \& Beaugé, 2002). Although the ionic regulations of the exchangers are similar in the two aforementioned preparations, they differ drastically in the case of MgATP. In mammalian heart NCX1 up-regulation takes place via the production and binding to the exchanger of phosphatidylinositol 4,5-bisphosphate $\left[\operatorname{PtdIns}(4,5) \mathrm{P}_{2}\right]$. On the other hand, in NCXSQ1 PtdIns $(4,5) \mathrm{P}_{2}$ is ineffective (DiPolo \& Beaugé, 2002), while MgATP upregulation requires the presence of a soluble cytosolic protein (Beaugé et al.,1996) present in both nerve axoplasm and optic ganglia. This protein of 132 amino acids, named ReP1NCXSQ (regulatory protein of the squid nerve sodium calcium exchanger), was cloned, overexpressed and purified. Functional experiments showed that to be active ReP1NCXSQ must be phosphorylated by a membrane-bound staurosporin-insensitive kinase and that MgATP might be necessary for this phosphorylation (Berberián et al., 2007). It should be noted that, in contrast to these previous functional studies, the protein that we studied here was found not to be phosphorylated. This protein was observed in several squid species, including Loligo pealei, Doryteuthis plei and Sepiotheutis sepioidea. Originally identified as a lipocalin (Berberián et al., 2009), this protein is actually placed at the frontier between the CRABP and FABP families (see \$3). FABPs and CRABPs are members of the same superfamily. A few CRABPs have been identified from invertebrates, one of which binds both palmitic acid and retinoic acid with high affinity (Gu et al., 2002; Folli et al., 2005). Members of both groups share a superimposable three-dimensional structure and relevant sequence similarity. Almost all members of the

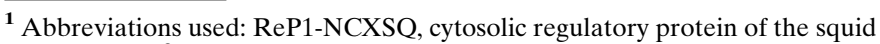
nerve $\mathrm{Na}^{+} / \mathrm{Ca}^{2+}$ exchanger; CRABP, cellular retinoic acid-binding protein; FABP, fatty acid-binding protein, NCX1, mammalian heart $\mathrm{Na}^{+} / \mathrm{Ca}^{2+}$ exchanger; NCXSQ1, squid nerve $\mathrm{Na}^{+} / \mathrm{Ca}^{2+}$ exchanger; MgATP, magnesium adenosine $5^{\prime}$-triphosphate; LBP, lipid-binding protein; CRBP, cellular retinolbinding protein; $\mathrm{H}_{\mathrm{i}}^{+}$, intracellular $\mathrm{H}^{+} ; \mathrm{Na}_{\mathrm{i}}^{+}$, intracellular $\mathrm{Na}^{+} ; \mathrm{Ca}_{\mathrm{i}}^{2+}$, intracellular $\mathrm{Ca}^{2+}$; PtdIns $(4,5) \mathrm{P}_{2}$, phosphatidylinositol 4,5-bisphosphate; NMG, $N$-methylD-glucamine; CHES, $N$-cyclohexyl-2-aminoethanesulfonic acid; MOPS, 3- $(N$ morpholino)propanesulfonic acid; HRMS, high-resolution mass spectrometry; ESI-MS, electrospray ionization mass spectrometry; LC-MS, liquid chromatography coupled to mass spectrometry.
}

FABP family bind fatty acids, while CRABPs usually bind retinoic acid. Depending on the structural elements and the database considered for classification, they can be included in the following families: cytosolic fatty-acid signature-containing proteins (PS00214, PROSITE; http://www.expasy.org/ prosite), fatty acid-binding protein-like (SCOP; http:// scop.mrc-lmb.cam.ac.uk/scop/) and homologous superfamily code 2.40.128.20 (CATH; http://www.biochem.ucl.ac.uk/bsm/ cath). Recently, Ono and Odani have proposed joining the FABPs, CRABPs and retinal CRBPs in a new superfamily named FABPs (Ono \& Odani, 2010). Therefore, this protein belongs to the FABP superfamily and is placed at the frontier between CRABPs and FABPs.

In this work, X-ray structural and mass-spectrometric studies of ReP1-NCXSQ suggest that it acts as a carrier of fatty acids and that palmitic acid is involved in the regulation of the $\mathrm{Na}^{+} / \mathrm{Ca}^{2+}$ exchanger from squid nerve. Despite the important advances made regarding the structure and phospholipid interactions of ReP1-NCXSQ1, the molecular mechanism underlying regulation remains unknown.

\section{Experimental procedures}

\subsection{Mutagenesis (Tyr128Phe)}

The point mutation of ReP1-NCXSQ was obtained using Phusion polymerase (Finnzymes, Finland) and pET28a-ReP1NCXSQ as a template. Following PCR, DpnI (Fermentas Inc., USA) incubation for $2 \mathrm{~h}$ at $310 \mathrm{~K}$ was used to digest parental DNA and select for mutation-containing amplified DNA. The introduction of the desired mutation into the recombinant plasmid was determined using automatic sequencing by the IGBMC core facility. The oligonucleotides used were from Invitrogen (Argentina). The primers used were as follows: forward primer, $5^{\prime}$-gtg tgc acc cgt att ttt aaa cgc gtg gat ctc- $3^{\prime}$; reverse primer, $5^{\prime}$-gag atc cac gcg ttt aaa aat acg ggt gca cac- $3^{\prime}$.

\subsection{ReP1-NCXSQ purification, preparation of nerve membrane vesicles, incubation and transport studies}

The expression and purification of His-tagged native and mutant ReP1-NCXSQ were performed as described previously (Berberián et al., 2009). Membrane vesicles were obtained from the optic nerves of two squid species (S. sepioidea and L. pealei), subjected to homogenization and differential centrifugation as described elsewhere (Beaugé et al., 1996; DiPolo et al., 1997) and loaded with $300 \mathrm{mM} \mathrm{NaCl}$, $0.1 \mathrm{~m} M$ Tris-EDTA, $30 \mathrm{~m} M$ Tris-MOPS (pH 7.3 at $293 \mathrm{~K}$ ). About $40 \%$ of them were in the inside-out orientation, making it possible to study intracellular exchanger-ligand interactions by their presence in the extravesicular solutions.

For incubation with the vesicles, $25 \mu \mathrm{l}$ of vesicles was incubated with $175 \mu \mathrm{l} \mathrm{ReP1-NCXSQ}$ at $10 \mathrm{mg} \mathrm{ml}^{-1}$ for $20 \mathrm{~s}$ at room temperature with $25 \mu \mathrm{l} 250 \mathrm{~m} M$ NMG-Cl, $50 \mathrm{~m} M$ HEPES-Tris pH 7.3, $1.14 \mathrm{~m} M \mathrm{CaCl}_{2}, 1.5 \mathrm{~m} M$ Tris-EGTA, $10 \mathrm{~m} M \mathrm{MgCl}_{2}, 2 \mathrm{~m} M$ vanadate with or without $25 \mu \mathrm{l} 5 M$ MgATP. The reaction was stopped with $4 \mathrm{~m} M$ Tris-EDTA and $1 \mathrm{~m} M$ vanadate (both final concentrations) at $273 \mathrm{~K}$. 
Table 1

$\mathrm{X}$-ray data-collection and refinement statistics for WT and Tyr128Phe mutant ReP1-NCXSQ crystals.

Values in parentheses are for the highest resolution shell.

\begin{tabular}{|c|c|c|}
\hline Protein & WT & Tyr128Phe mutant \\
\hline \multicolumn{3}{|l|}{ Data collection } \\
\hline $\mathrm{X}$-ray beamline and source & X06DA [PXIII], SLS & X06DA [PXIII], SLS \\
\hline Wavelength $(\AA)$ & 0.9000 & 0.91960 \\
\hline Space group & $P 2_{1} 2_{1} 2_{1}$ & $P 3_{2}$ \\
\hline Asymmetric unit content & Monomer & Trimer \\
\hline Unit-cell parameters (A) & $\begin{array}{l}a=40.32, b=49.58 \\
\quad c=60.47\end{array}$ & $a=80.26, c=59.34$ \\
\hline Resolution range $(\AA)$ & $50.0-1.28(1.33-1.28)$ & 50.0-1.90 (1.97-1.90) \\
\hline No. of observations & 175673 & 103423 \\
\hline No. of unique reflections & 31531 & 33356 \\
\hline Multiplicity & $5.6(5.2)$ & $3.1(3.1)$ \\
\hline Completeness (\%) & $98.7(97.6)$ & $98.8(98.3)$ \\
\hline$R_{\text {merge }}{ }^{1}(\%)$ & $4.3(37.6)$ & $3.5(37.5)$ \\
\hline Mean $I / \sigma(I)$ & $32.8(4.1)$ & $32.3(3.2)$ \\
\hline \multicolumn{3}{|l|}{ Refinement } \\
\hline $\begin{array}{l}\text { Refinement resolution } \\
\quad \text { range }(\AA)\end{array}$ & $30.25-1.28$ & $34.76-1.90$ \\
\hline$R$ factor $(\%)$ & 13.4 & 20.8 \\
\hline$R_{\text {free }}(\%)$ & 17.1 & 26.6 \\
\hline $\begin{array}{l}\text { No. of reflections used } \\
\text { in refinement }\end{array}$ & 31468 & 31990 \\
\hline $\begin{array}{l}\text { Model used for } \\
\text { molecular replacement }\end{array}$ & 1yiv & 1yiv \\
\hline R.m.s.d. bonds (§) & 0.008 & 0.007 \\
\hline R.m.s.d. angles $\left({ }^{\circ}\right)$ & 1.291 & 1.099 \\
\hline No. of protein atoms & 1267 & 3801 \\
\hline No. of solvent molecules & 252 & 363 \\
\hline \multicolumn{3}{|l|}{ Ramachandran plot } \\
\hline Favoured (\%) & 98.53 & 97.02 \\
\hline Accepted (\%) & 1.47 & 2.68 \\
\hline Outliers (\%) & 0 & 0.3 \\
\hline
\end{tabular}

${ }^{1} R_{\text {merge }}=\sum_{h k l} \sum_{i}\left|I_{i}(h k l)-\langle I(h k l)\rangle\right| / \sum_{h k l} \sum_{i} I_{i}(h k l)$.

The membrane vesicles were separated by centrifugation at $12000 \mathrm{rev} \mathrm{min}^{-1}$ for $30 \mathrm{~min}$.

The assays for ion transport consisted of measuring the $\mathrm{Na}^{+}-$ gradient-dependent ${ }^{45} \mathrm{Ca}^{2+}$ uptake (forward mode in insideout vesicles; Berberián et al., 2009). The external solutions consisted of low $(20 \mathrm{~m} M)$ or high $(300 \mathrm{~m} M) \mathrm{NaCl}, 1 \mathrm{~m} M$ free $\mathrm{Mg}^{2+}, 0.2 \mathrm{~m} M$ vanadate, $0.15 \mathrm{~m} M$ EGTA, $20 \mathrm{~m} M$ Tris-MOPS (pH 7.3 at $293-295 \mathrm{~K}$ ) and $1 \mu M \mathrm{Ca}^{2+}$; when present, MgATP was at $1 \mathrm{~m} M$ concentration. Iso-osmolar amounts of NMG-Cl compensated for the reduction in $\mathrm{Na}^{+}$concentration. The $\mathrm{Na}^{+}-$ gradient-dependent $\mathrm{Ca}^{2+}$ uptake was taken as the difference between that observed at low and high $\mathrm{Na}^{+}$concentration; the incubation time was $10 \mathrm{~s}$ and the temperature was $293-295 \mathrm{~K}$. The transport studies were performed for the wild type (WT) and the mutant.

\subsection{Crystallization and structure determination of WT and Tyr128Phe mutant ReP1-NCXSQ}

Crystals of WT ReP1-NCXSQ were grown by hanging-drop vapour diffusion at $277 \mathrm{~K}$. The protein was concentrated to $10 \mathrm{mg} \mathrm{ml}^{-1}$ in $10 \mathrm{~m} M$ Tris- $\mathrm{HCl} \mathrm{pH} 7.4,150 \mathrm{mM} \mathrm{NaCl}$. For crystal growth, a $2 \mu \mathrm{l}$ drop of protein solution was mixed with an equal volume of precipitating solution $(200 \mathrm{mM} \mathrm{KCl}, 35 \%$
PEG 2000 MME) and equilibrated against $0.5 \mathrm{ml}$ of the same solution. Typically, rod-like crystals appeared in $2-3 \mathrm{~d}$ and continued to grow to maximum dimensions of $300 \times 100 \times$ $50 \mu \mathrm{m}$. They were cryoprotected by transfer into precipitating solution plus $5 \%$ ethylene glycol and were flash-cooled in liquid ethane prior to data collection.

An initial data set was collected to 1.8 A resolution with the laboratory source. The data were processed with $H K L-2000$ (Otwinowski \& Minor, 1997) and the structure was solved by molecular replacement (Navaza, 1994) using PDB entry 1yiv (Hunter et al., 2005). The correct sequence was fitted with ARP/wARP (Perrakis et al., 1997) and the structure was refined with REFMAC5 (Murshudov et al., 2011). A second data set was collected to a resolution of $1.28 \AA$ on the X06DA beamline at the Swiss Light Source (SLS). The structure was further refined at $1.28 \AA$ resolution with REFMAC5 and PHENIX (Adams et al., 2002) to an $R$ factor of $13.4 \%$ and an $R_{\text {free }}$ of $17.1 \%$. The model and the diffraction data have been deposited in the Protein Data Bank with code 3ppt. Note that the differences in the occupancies of protein and ligand atoms in the PDB deposition are the result of independent refinement. For data-collection and refinement statistics, see Table 1.

For the Tyr128Phe mutant of ReP1-NCXSQ, the protein was also concentrated to $10 \mathrm{mg} \mathrm{ml}^{-1}$ in $10 \mathrm{~m} M$ Tris- $\mathrm{HCl} \mathrm{pH}$ 7.4, $150 \mathrm{mM} \mathrm{NaCl}$, but the crystals were obtained using a different crystallization condition. Rod-like crystals appeared in $100 \mathrm{~m} M$ CHES $\mathrm{pH} 9.5,30 \%$ PEG 3000. A data set was collected to $1.9 \AA$ resolution on the X06DA beamline at SLS. The structure was solved by molecular replacement to an $R$ factor of $20.8 \%$ and an $R_{\text {free }}$ of $26.6 \%$. The model and the diffraction data have been deposited in the Protein Data Bank with code 3pp6. For data-collection and refinement statistics, see Table 1.

\subsection{Native mass spectrometry}

Prior to mass-spectrometric (MS) experiments, the proteins were buffer-exchanged against $10 \mathrm{mM}$ ammonium acetate $\mathrm{pH}$ 6.8 using microcentrifuge gel-filtration columns (Zeba $0.5 \mathrm{ml}$; Thermo Scientific, Rockford, Illinois, USA). Protein concentrations were determined spectrophotometrically. Native MS analyses were performed using an electrospray time-of-flight (ESI-TOF) mass spectrometer (LCT; Waters, Manchester, England) equipped with an automated chip-based nanoESI source (Triversa Nanomate; Advion Biosciences, Ithaca, New York, USA) operating in the positive-ion mode. External calibration was performed using the multiply charged ions produced by $2 \mu M$ horse heart myoglobin diluted in $1: 1(v: v)$ water:acetonitrile acidified with $1 \%(v / v)$ formic acid. The molecular mass, integrity and homogeneity of the proteins were first checked under denaturing conditions by diluting the proteins to $2 \mu M$ in $1: 1(v: v)$ water:acetonitrile acidified with $1 \%(v / v)$ formic acid. The measured molecular masses of WT ReP1-NCXSQ (15 597.6 $\pm 0.1 \mathrm{Da})$ and ReP1-NCXSQ Tyr128Phe (15 582.0 $\pm 0.1 \mathrm{Da})$ were found to be in agreement with the masses calculated on the basis of the amino-acid sequences with deletion of the $\mathrm{N}$-terminal methionine. Native 
MS experiments require careful instrumental tuning to find the best compromise between ion desolvation/transmission through the mass spectrometer and the preservation of weak noncovalent interactions in the gas phase. In this study, instrumental optimization especially concerned the accelerating voltage applied on the sample cone $\left(V_{\mathrm{c}}\right)$ and the pressure in the first pumping stage of the mass spectrometer $\left(P_{\mathrm{i}}\right)$. While $P_{\mathrm{i}}$ was fixed at $750 \mathrm{~Pa}, V_{\mathrm{c}}$ was fixed at $10 \mathrm{~V}$ for protein-fatty acid complex detection. Native MS analysis were performed by diluting buffer-exchanged proteins to $5 \mu M$ in $\mathrm{H}_{2} \mathrm{O}$. Data analysis was performed with MassLynx 4.0 (Waters, Manchester, England). The peak intensities at the three charge states $+7,+8$ and +9 of the different species (apoprotein and holoprotein) were used to calculate the ratios of each detected species.

\subsection{High-resolution LC-MS analysis}

LC-MS analyses were performed on an Agilent 1100 HPLC system (Agilent Technologies, Palo Alto, California, USA) coupled to an electrospray quadrupole/time of flight-type mass spectrometer (MicrOTOF Q; Bruker Daltonics, Bremen, Germany). $1 \mu \mathrm{g}$ protein was injected onto a Zorbax SB-C18 Rapid Resolution Cartridge $2.1 \times 30 \mathrm{~mm}, 3.5 \mu \mathrm{m}$ particle-size, $80 \AA$ bore-diameter column (Agilent Technologies). The solvent system consisted of $5 \mathrm{~m} M$ aqueous ammonium acetate (solvent $A$ ) and a mixture of $75 \%$ acetonitrile, $20 \%$ 2-propanol and $5 \% 50 \mathrm{~m} M$ aqueous ammonium acetate (solvent $B$ ). While the proteins were excluded from the column owing to the narrow bore diameter ( $80 \AA$ ), the fatty acids bound to the proteins were trapped on the column at $15 \%$ solvent $B$ and elution was performed at a flow rate of $0.25 \mathrm{ml} \mathrm{min}{ }^{-1}$ with a $15-90 \%$ solvent $B$ gradient over 4 min followed by $90 \%$ solvent $B$ for $4 \mathrm{~min}$ and $100 \%$ solvent $B$ for a further $4 \mathrm{~min}$ before reconditioning of the column at $15 \%$ solvent $B$. The MicrOTOF Q was operated in the negative-ion mode. The performance and resolution were verified using Tunemix (Agilent Technologies, USA). The resolution at $\mathrm{m} / \mathrm{z} 602$ was 15000 . Mass calibration of the TOF was achieved prior to analysis between $\mathrm{m} / \mathrm{z} 50$ and 1200 using lithium formate $(10 \mathrm{~m} M)$ in order to obtain a mass precision of \pm 10 p.p.m. The capillary voltage was set to $4500 \mathrm{~V}$. The complete system was fully controlled by Compass/HyStar software (Bruker Daltonics, Germany). Prior to protein injection, a blank consisting of $1 \mu \mathrm{l}$ of the matrix in which the protein was dissolved (1 $\mathrm{m} M$ ammonium acetate) was injected. The blank was then substracted from the protein analysis using the software Metabolite Detect (Bruker Daltonics, Germany).
Data analysis was performed using DataAnalysis 4 (Bruker Daltonics, Germany). In order to identify the fatty acids eluted from the column, we used SmartFormula (a function of DataAnalysis 4), which can calculate an empirical formula from an exact mass measurement. We calculated the formulae of all peaks eluted from the column allowing \pm 10 p.p.m. error on the mass of the generated formulae.

\subsection{Sequence alignment}

An initial BLASTx search (default conditions) at the National Center for Biotechnology Information (NCBI) showed that ReP1-NCXSQ has the greatest number of hits with cytosolic retinoic acid-binding proteins (CRABPs) and fatty acid-binding proteins (FABPs). In order to discern which proteins belong to which subgroups, we aligned ReP1-NCXSQ 
with vertebrate and invertebrate CRABPs and FABPs using the ClustalX v.2.0.10 software (Larkin et al., 2007). ClustalX was used because of the lack of structural data for invertebrate homologues. Selected sequences from GenBank were used to develop a neighbour-joining tree using $M E G A$ (Kumar et al., 1993). The significance of branching points was assessed by bootstrapping with 500 pseudoreplicates.

\section{Results}

\subsection{ReP1-NCXSQ belongs to the} CRABP family and the FABP superfamily

Alignment of ReP1-NCXSQ with CRABPs from invertebrates (Supplementary Fig. $\mathrm{S}^{2}$ ) revealed a similarity of $70 \%$ and an identity of $37 \%$, while that with vertebrate CRABPs gave a similarity of $66 \%$ and an identity of $30 \%$ (Supplementary Fig. S2 ${ }^{2}$ ), suggesting that it belongs to the CRABP family of the FABP superfamily (Ono \& Odani, 2010). In particular, it presents the fingerprint of the FABP superfamily and most of its conserved amino acids (Furuhashi \& Hotamisligil, 2008; Esteves \& Ehrlich, 2006). Supplementary Fig. $\mathrm{S}^{2}$ shows the conserved amino acids of H-FABPs and CRABPs that are shared with the deduced ReP1NCXSQ sequence. The sequence alignment from $B L A S T$ shows that the closest sequence is that of the retinoic acid/retinol-binding protein from shrimp (gb|AAL68638.1|AF458289_1). It also shows a strong similarity, both in sequence and structure, to myelin P2 proteins from vertebrates.

When ReP1-NCXSQ was aligned with invertebrate FABPs similarity and identity were considerably lower (23\% similarity and $7.5 \%$ identity; Supplementary Fig. $\mathbf{S} 4^{2}$ ). To further explore the position of the squid protein in the protein superfamily, a phylogenetic reconstruction was performed. The ReP1-NCXSQ sequence clusters with Metapenaeus ensis CRABP and forms a sister group to a cluster of insect CRABPs. Both clades are also clustered with invertebrate FABPs (Fig. 1). Moreover, if we restrict the comparison to proteins from arthropods and even insects, this trend is supported (Supplementary Figs. S5 and $\mathbf{S 6}^{2}$ ). A detailed discussion of the assignment as FABP or CRABP is given in the Supplementary Material. ${ }^{2}$

\footnotetext{
${ }^{2}$ Supplementary material has been deposited in the IUCr electronic archive (Reference: EN5495). Services for accessing this material are described at the back of the journal.
}

\subsection{Mass-spectrometric characterization of ReP1-NCXSQ and its Tyr128Phe mutant}

Prior to crystallization studies, ReP1-NCXSQ and its Tyr128Phe mutant were characterized in depth by a combination of MS-based techniques. Native MS analyses were first conducted in order to detect any unknown ligand arising from the Escherichia coli production medium and bound to recombinant ReP1-NCXSQ. Liquid chromatography coupled to high-resolution mass spectrometry (LC-HRMS) was then used to identify bound compounds.

Fig. 2 presents mass spectra obtained under native conditions for both recombinant ReP1-NCXSQ and its Tyr128Phe mutant. In the wild-type recombinant protein (WT ReP1NCXSQ), $44 \%$ of the ions detected correspond to species with an unknown ligand bound to the protein. Among these, 21\% had a mass increase of $255 \pm 1 \mathrm{Da}$, while the other $23 \%$ had a mass increase of $283 \pm 1 \mathrm{Da}$ (Fig. $2 a$ ).

As fatty acids are molecules that are known to fortuitously interact with proteins such as nuclear receptors (Bourguet et al., 2000; de Urquiza et al., 2000; Elviri et al., 2001; Potier et al., 2003) and because ReP1-NCXSQ belongs to the FABP 
Table 2

Summary of identified fatty acids from HRMS measurements (Fig. 3).

Theoretical molecular masses are indicated as $[M-\mathrm{H}]^{-}$ions. n.i., not identified.

\begin{tabular}{|c|c|c|c|c|}
\hline Peak No. & Fatty acid & $\begin{array}{l}\text { Molecular } \\
\text { formula }\end{array}$ & $\begin{array}{l}\text { Theoretical } \\
\text { monoisotopic } \\
\text { mass (Da) }\end{array}$ & $\begin{array}{l}\text { Measured } \\
\text { monoisotopic } \\
\text { mass (Da) }\end{array}$ \\
\hline 1 & Docosahexaenoic acid (DHA) & $\mathrm{C}_{22} \mathrm{H}_{32} \mathrm{O}_{2}$ & 327232 & $327232(4)$ \\
\hline 3 & Linoleic acid & $\mathrm{C}_{18} \mathrm{H}_{32} \mathrm{O}_{2}$ & 279232 & $279232(2)$ \\
\hline \multirow[t]{2}{*}{4} & Dihomo- $\gamma$-linoleic acid (DGLA) & $\mathrm{C}_{20} \mathrm{H}_{34} \mathrm{O}_{2}$ & 305248 & 305247 (1) \\
\hline & or eicosatetraenoic acid (ETA) + n.i. & n.i. & n.i. & $267232(3)$ \\
\hline
\end{tabular}

(a) WT ReP1-NCXSQ

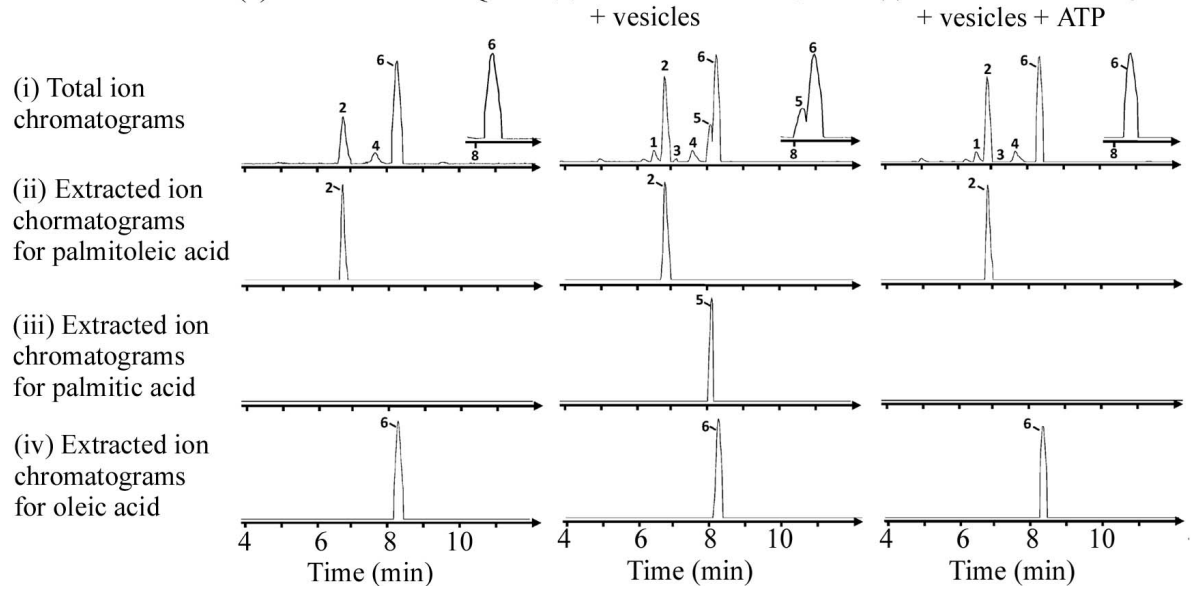

Figure 3

Identification of fatty acids bound to ReP1-NCXSQ by high-resolution LC-MS analysis (LCHRMS). LC chromatograms of fatty-acid binding to $(a)$ wild-type ReP1-NCXSQ, $(b)$ ReP1NCXSQ pre-incubated with nerve vesicles without MgATP and (c) ReP1-NCXSQ pre-incubated with nerve vesicles in the presence of MgATP. (i) Represent total ion chromatograms and (ii-iv) correspond to extracted ion chromatograms of palmitoleic (ii), palmitic (iii) and oleic (iv) acids, respectively.

superfamily, palmitic/palmitoleic acids could be proposed as possible interacting compounds corresponding to the $15853 \pm$ $1 \mathrm{Da}$ complex, while linoleic/oleic acid may correspond to the $15881 \pm 1$ Da compound (Fig. 2a). The binding capabilities of palmitoleic, palmitic and oleic acids to both ReP1-NCXSQ and the Tyr128Phe mutant were investigated by the direct addition of three molar equivalents of each individual fatty acid to wild-type ReP1-NCXSQ protein (Figs. 2b-2e). As expected, depending on the fatty acid spiked, subsequent increases of the $\mathrm{m} / \mathrm{z}$ ratio corresponding to either palmitoleic, palmitic or oleic acid bound to WT ReP1-NCXSQ were observed (Figs. $2 b-2 d$ ). Interestingly, for the Tyr128Phe mutant the native MS results show a lower occupancy for fatty acids. Only $12 \%$ of the detected species could correspond to an ReP1-NCXSQ-palmitic/palmitoleic acid complex and 7\% to an ReP1-NCXSQ-linoleic/oleic acid complex (Fig. 2e).

High-resolution LC-MS experiments (LC-HRMS) were then performed to deduce molecular formulae from exact mass measurements. LC chromatograms obtained with the
WT ReP1-NCXSQ protein (Fig. $3 a$ and Table 2) show that there is no peak corresponding to either palmitic or linoleic acid. Conversely, a peak corresponding to palmitoleic acid was clearly identified. Together, these MS results prompted us to conclude that oleic and palmitoleic acids correspond to the $15881 \pm 1$ and $15853 \pm 1$ Da complexes detected, respectively.

\subsection{Mass-spectrometric characteriza- tion of the fatty acid involved in the regulation of NCXSQ}

In order to assess the physiological relevance of the identified fatty acids, LC-HRMS experiments were also conducted using the protein incubated with squid nerve vesicles. As previously described (Fig. 3a), no palmitic acid was detected within the WT ReP1-NCXSQ sample.

After incubation of ReP1-NCXSQ with squid nerve vesicles, very similar LC chromatograms were obtained both in the absence and the presence of MgATP (Figs. $3 b$ and $3 c$ ). However, in the absence of MgATP an additional peak (peak 5 in Fig. $3 b$ ) was detected that was absent in the presence of MgATP. HRMS analyses clearly identified palmitic acid as the only component present in peak 5 (Fig. 3 and Table 2). This result can be interpreted in the following way: (i) in WT ReP1NCXSQ there is no palmitic acid (no peak 5 in Fig. 3a); (ii) after vesicle incubation without MgATP palmitic acid binds to the protein (peak 5 in Fig. 3b); (iii) after vesicle incubation with MgATP palmitic acid is no longer detected and may thus have been transferred to the exchanger (no peak 5 and narrow peak 6 in Fig. 3c).

In order to investigate the role of Tyr128 in fatty-acid binding after vesicle incubation, similar LC-HRMS experiments were perfomed on the Tyr128Phe mutant (Supplementary Fig. S8). Under the same conditions, mutated ReP1NCXSQ is no longer able to bind palmitic acid. This result 


\section{research papers}

Table 3

Effect of WT and mutant ReP1-NCXSQ on the MgATP stimulation of $\mathrm{Na}^{+}$-gradient-dependent $\mathrm{Ca}^{2+}$ uptake.

\begin{tabular}{ll}
\hline Protein type & $\begin{array}{l}\text { MgATP stimulation of } \mathrm{Na}^{+} \text {-gradient-dependent } \\
\mathrm{Ca}^{2+} \text { uptake }\left(\mathrm{nmol} \mathrm{mg}^{-1} \text { in } 10 \mathrm{~s}\right)\end{array}$ \\
\hline WT, no MgATP & $0.51 \pm 0.01$ \\
WT, with MgATP & $1.25 \pm 0.03$ \\
Tyr128Phe, with MgATP & $0.53 \pm 0.025$ \\
\hline
\end{tabular}

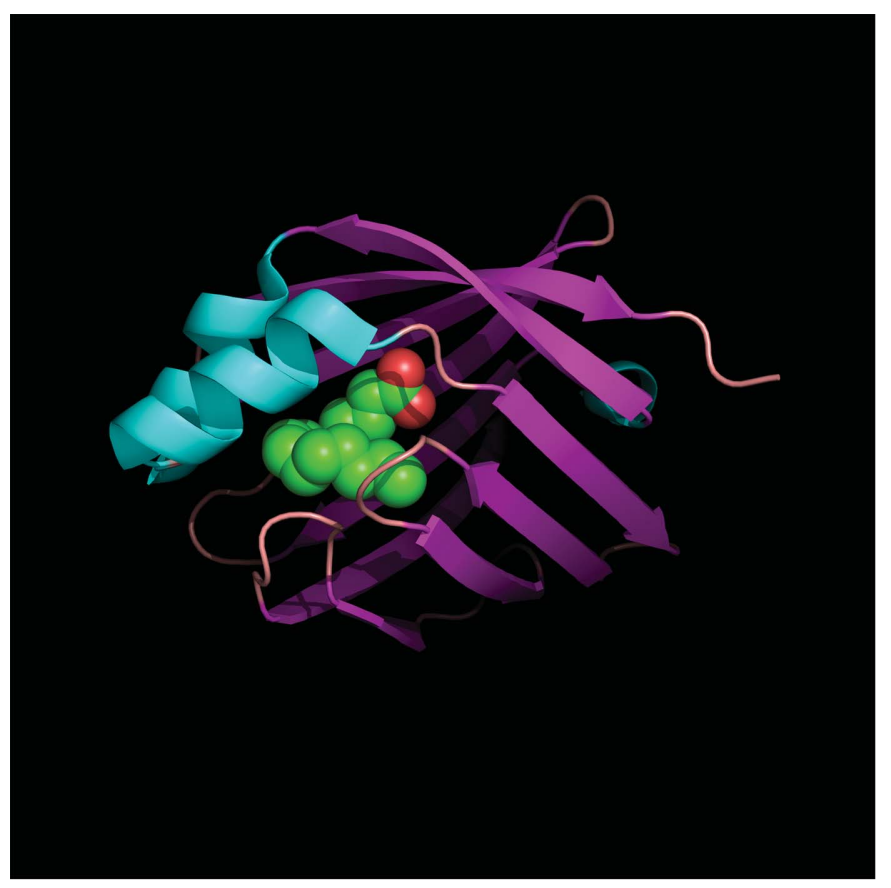

$(a)$

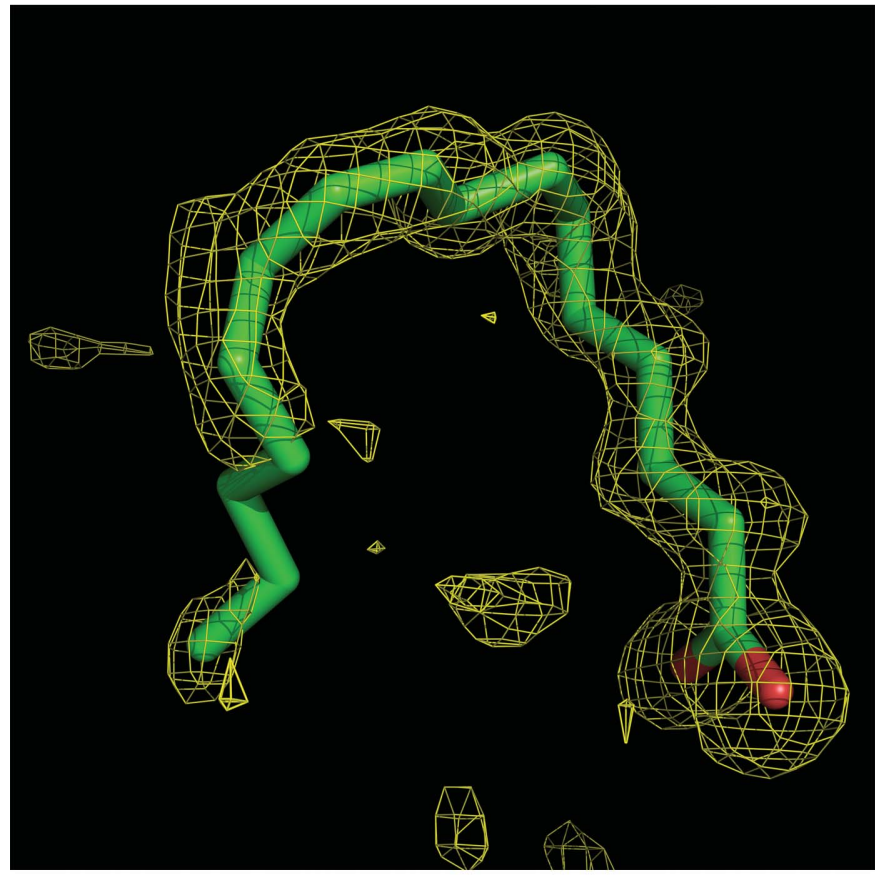

(b) strongly suggests that Tyr128 is directly involved in palmitic acid transport.

In summary, even when the actual details of the interaction of ReP1-NCXSQ with the exchanger remain elusive (Berberián et al., 2009), the LC-HRMS strongly suggests that ReP1-NCXSQ transports palmitic acid and that Tyr128 is essential for this function.

\subsection{Crystal structures of wild-type ReP1-NCXSQ and its Tyr128Phe mutant}

The crystal structures of wild-type ReP1-NCXSQ and the Tyr128Phe mutant and their abilities to bind the fatty acid inside the barrel were analyzed. The structures fold in a $\beta$-sandwich with ten $\beta$-strands, as is typical for lipid-binding proteins (Fig. 4a). For the wild type, the difference maps clearly show the presence of a lipid arising from the $E$. coli production medium which is ordered up to $\mathrm{C} 12$ (Fig. $4 b$ ). In this chain, the high-resolution structure (1.28 $⿱$ ) $)$ of WT ReP1NCXSQ allows the identification of a double bond between C9 and C10 (1.33 $\AA$ ) of the aliphatic chain. The major conformation of the carboxylate head makes two strong contacts with $\operatorname{Arg} 126$ (2.66 $\AA$ ) and Tyr128 (2.60 ̊) (Fig. 4c). The $\mathrm{O}-\mathrm{O}$ distance of $2.60 \AA$ is close to the limit of a lowbarrier hydrogen bond (2.55 А; Schiøtt et al., 1998). Such an interaction has been observed previously with a distance of $2.50 \AA$ (Marr et al., 2006).

Following the indications of native mass-spectrometric and LC-HRMS experiments, electron-density signals observed for

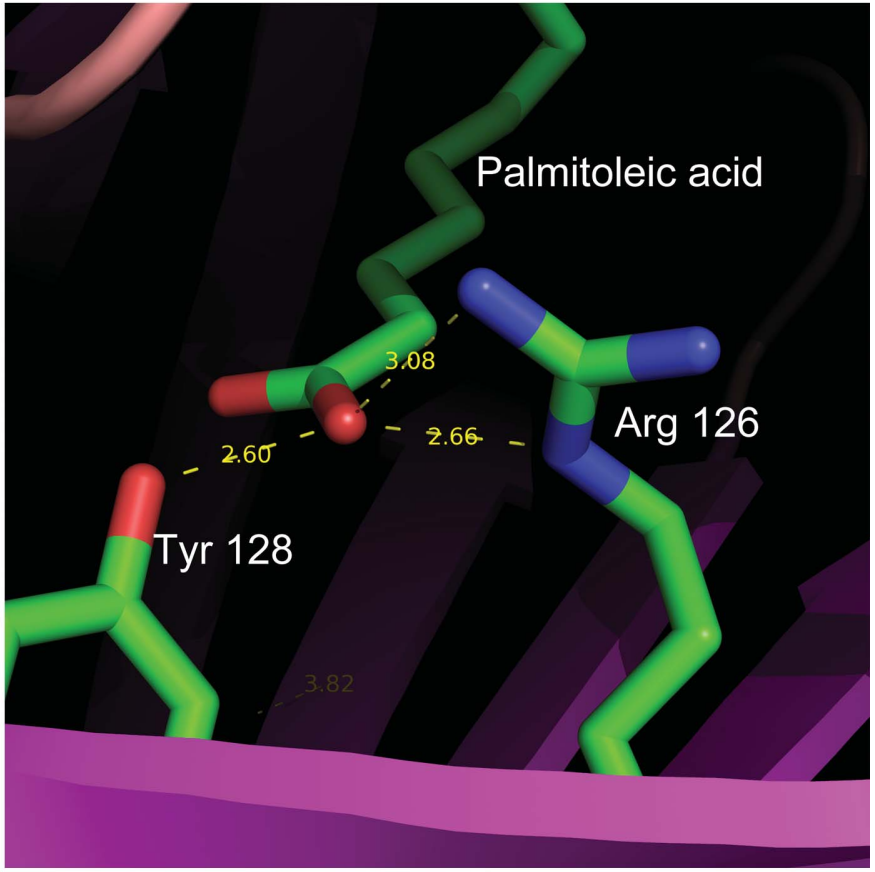

(c)

\section{Figure 4}

Crystal structure of ReP1-NCXSQ. (a) Ribbon representation of the structure of WT ReP1-NCXSQ with the palmitoleic acid shown as a CPK model. Note that the structure folds in a $\beta$-sandwich with ten $\beta$-strands that is typical of lipid-binding proteins. (b) Difference map of WT ReP1-NCXSQ showing the presence of palmitoleic acid, contoured at 3.0 $\sigma$. Note the clear signal for the carboxylate head and the aliphatic chain up to $\mathrm{C} 12$ and the disorder at the end of the aliphatic chain. (c) Hydrogen-bond contacts of the head of palmitoleic acid with Arg126 and Tyr128. 
ReP1-NCXSQ were interpreted as the disordered tail (C13C16) of palmitoleic acid. This disorder had previously been observed with oleic acid (Sacchettini et al., 1992). This fatty acid tightly fits the interior of the protein. Similar observations have been made with palmitic acid (Sacchettini et al., 1989; Scapin et al., 1993; Jakobsson et al., 2003). The fact that the fatty acid in the interior of the ReP1-NCXSQ barrel seems to be stabilized by a relatively short hydrogen bond connecting to Tyr128 offers the possibility of investigating whether this bond is necessary for promotion of the stimulation of $\mathrm{Na}^{+} /$ $\mathrm{Ca}^{2+}$ exchanger by MgATP. The functional analysis results described in Table 3 show that the MgATP up-regulation of the exchanger is strongly diminished by Tyr128Phe-mutated ReP1-NCXSQ protein compared with the WT.
The Tyr128Phe mutant crystal structure provides difference maps showing a signal for the palmitoleic acid, with disorder of the carboxylate head and of the aliphatic chain C7-C16 (Fig. 5a). C atoms C7-C12, which are clearly seen in the WT map, are not seen in the Tyr128Phe mutant. The carboxylate head is significantly more disordered than in the WT structure. Fig. 5(b) shows a comparison between the WT and Tyr128Phe mutant structures, showing that they are very similar except in the loop containing Phe58; this amino-acid residue, which is a main component of the so-called portal region, is displaced by almost $5 \AA$ A. This can be better observed in Figs. 5(c) and 5(d), where the movement of Phe58 opens a channel leading into the cavity. This flexibility of the portal region has previously been observed in other structures (Reese-Wagoner et al., 1999;

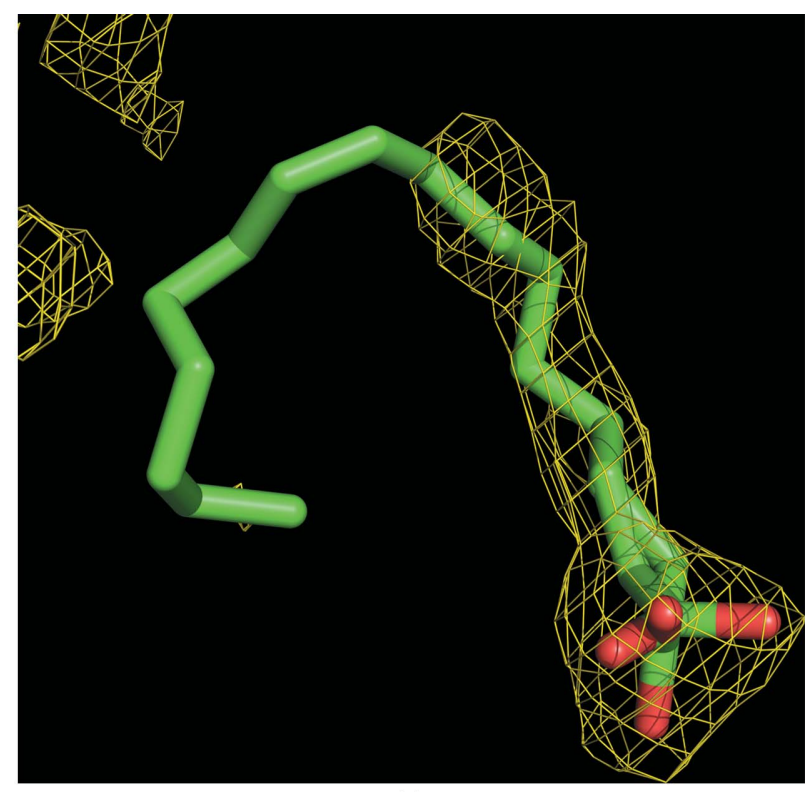

(a)

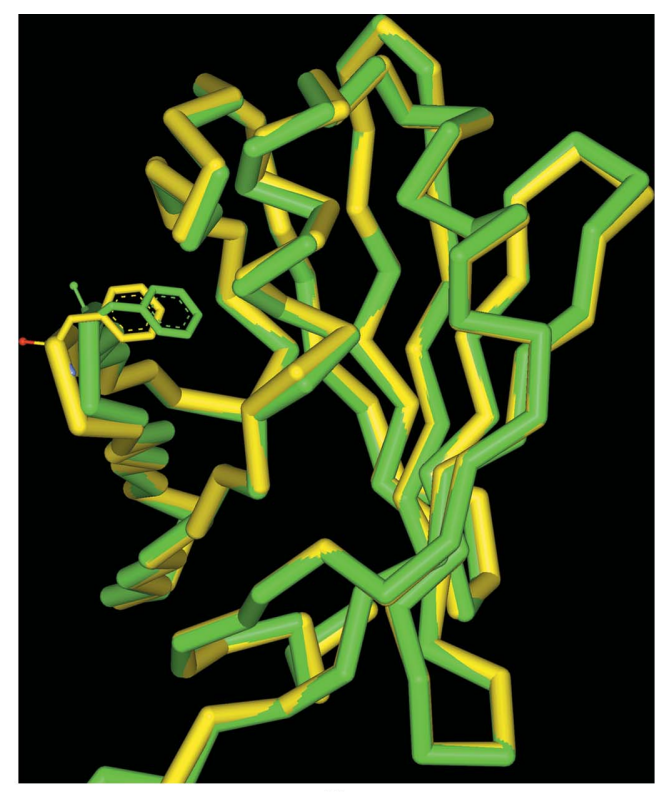

(b)
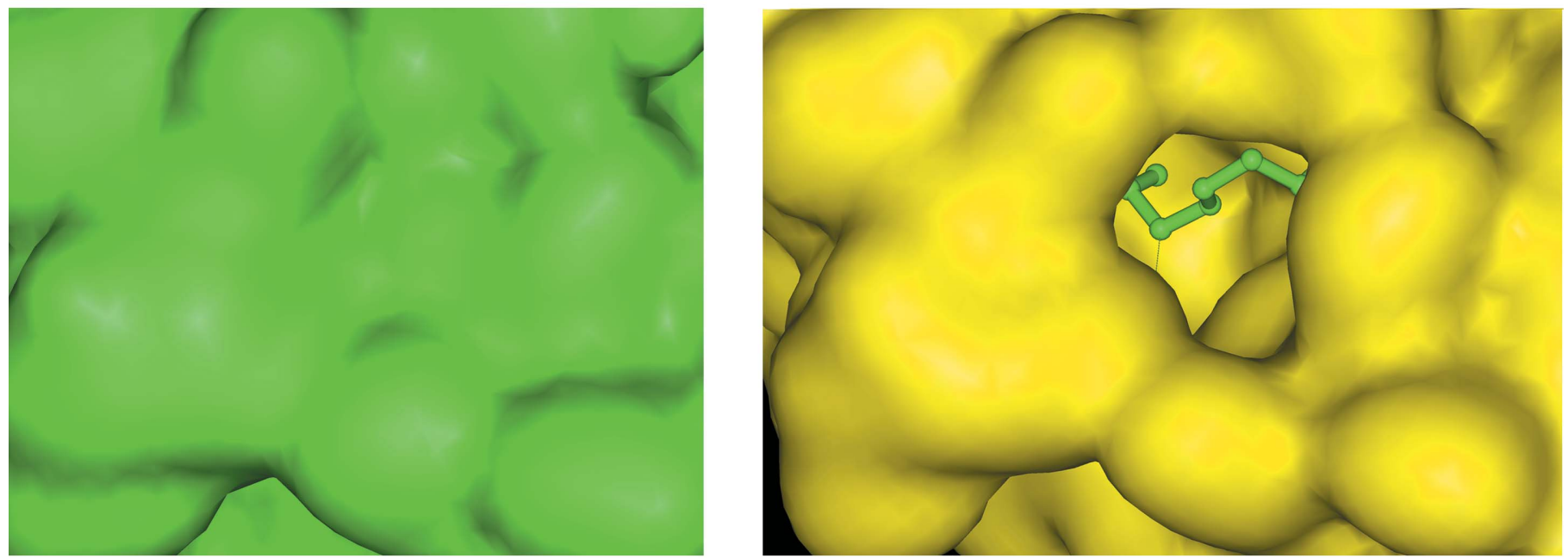

(c)

\section{Figure 5}

Comparison between WT and Tyr128Phe mutant ReP1-NCXSQ. (a) Difference map showing the presence of palmitoleic acid in the Tyr128Phe mutant, contoured at 3.0 $\sigma$. Note the disordered signal for the carboxylate head and that the clear signal for palmitoleic acid stops after $\mathrm{C} 8$, showing disorder from $\mathrm{C} 8$ to the end of the aliphatic chain. (b) Comparison of the structures of WT (green) and Tyr128Phe mutant ReP1-NCXSQ (yellow) showing the C ${ }^{\alpha}$ trace and Phe58. (c) Comparison of the surface around Phe58 for WT (green, left) and Tyr128Phe (yellow, right) ReP1-NCXSQ. The palmitoleic acid (WT position) is shown in green ball-and-stick representation. 
Xu et al., 1993). This channel is closed in the WT-palmitoleic acid complex. In other words, in the WT structure the position of Phe58 is stabilized by a hydrophobic contact between Phe 58 CE1 and C10 of palmitoleic acid (3.57 ̊ distance), whereas in the Tyr128Phe mutant the palmitoleic acid tail is disordered, leading to a double conformation of the Phe58 loop with equal occupancies.

It is also worth mentioning the closed position of Phe58 when bound to WT ReP1-NCXSQ. A similar position has only previously been observed when activating ligands were bound to FABP4 (Gillilan et al., 2007).

\section{Discussion}

This work presents crystallographic and mass-spectrometric results on the ReP1-NCXSQ protein, which is essential for MgATP up-regulation of the squid nerve $\mathrm{Na}^{+} / \mathrm{Ca}^{2+}$ exchanger. A sequence alignment shows that it shares primary structure with the CRABP family of the FABP superfamily. The fingerprint of the FABPs (see Furuhashi \& Hotamisligil, 2008, and references therein) and most of the conserved amino acids described for FABPs from invertebrates (Esteves \& Ehrlich, 2006) are present in ReP1-NCXSQ.

The presence in this protein of the characteristic binding residues involved in the interaction with ligand carboxylate head groups, a feature pertaining to several FABPs and to CRABPs, and the close phylogenetic relationships with both the vertebrate heart-type FABPs and CRBPs/CRABPs makes it difficult to assign it to either the FABPs or the CRABPs. On the other hand, the three-dimensional structures of FABPs and CRABPS are superimposable (Supplementary Fig. S7). Taking together sequence and phylogenetic data and binding results, we assume that Rep1-NCXSQ is at the frontier between the subfamilies, with several elements that lead us to place it among the CRABPs.

Recombinant ReP1-NCXSQ expressed in E. coli contains palmitoleic acid in the barrel. The fatty acid is held by hydrogen bonds to Arg126 and Tyr128 (shortest bond). The point mutation Tyr128Phe suggested that Tyr128 is a critical residue that is essential for fatty acid binding in the barrel and activity studies of the WT and the Tyr128Phe mutant showed that Tyr128 is necessary for MgATP activation of the $\mathrm{Na}^{+} / \mathrm{Ca}^{2+}$ exchanger. The crystal and mass-spectrometric analyses indicate the presence of palmitoleic acid attached to Tyr128 and Arg126 by hydrogen bonds and indicate that the Tyr128Phe mutant loses, to a large extent if not completely, the capability to retain the ligand inside the barrel when purified from the expression system. This is accompanied by disorder of the palmitoleic acid and a structural change at the level of the so-called portal region (the Phe58 loop), which is displaced by almost $5 \AA$, opening a channel leading into the cavity.

Identification of the biological ligand is not obvious. The most likely candidates are (i) palmitic acid, which is abundant

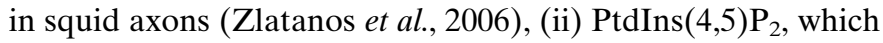
regulates the cardiac exchanger, and (iii) retinoic acid (RA), as suggested by the fact that ReP1-NCXSQ has a sequence profile that places it next to the CRABP family. In this regard, it is interesting that ReP1-NCXSQ binds polyphosphoinositides and phosphatidic acid but does not seem to bind other membrane components such as cholesterol, sphingomyelin, phosphoserine, phosphoethanolamide or PtdIns (Berberián et al., 2009).

MeCRABP was the first crustacean member of the retinoid/ fatty acid-binding protein family to be cloned. A study indicated that the protein binds to both RA and retinal with similar affinity (Gu et al., 2002). Note, however, that evidence for roles of retinoic signalling outside the chordates and the evolutionary origin of retinoic signalling itself still remain elusive.

Palmitic acid is indeed a good candidate for the regulatory function; there are several examples in the literature in which it acts as a regulatory biological ligand, sometimes on membrane transporters. (i) In Saccharomyces cerevisiae the YPTI gene encoding a RAS-like guanine nucleotide-binding protein is essential for cell viability. Mutations of two consecutive cysteines at the carboxyl-terminus, either by deletion or substitution by serines, resulted in a nonfunctional protein and also a loss of palmitoylation as estimated by $\left[{ }^{3} \mathrm{H}\right]$-palmitic acid binding (Molenaar et al., 1988). (ii) In rat L6 cells, saturated fatty acids, including palmitate, induce peripheral insulin resistance by impairing GLUT4 translocation in response to insulin (Tsuchiya et al., 2010). (iii) In the skeletal muscle L6 cell line, the acute effects of palmitic acid as followed by immunofluorescence changes included rapidly induced GLUT4 translocation and stimulated glucose uptake ( $\mathrm{Pu}$ et al., 2011). (iv) In mammalian heart, inhibition of the sodium pump by phospholemman (PLM) required palmitoylation of the PLM; the absence of palmitoylation rendered PLM ineffective as, unexpectedly, did reduced PLM phosphorylation. Therefore, palmitoylation of all FXYD proteins, which have conserved intracellular cysteines, may be a universal means of regulating the sodium pump (Tulloch et al., 2011). (v) In neurons, dopamine transporters (DATs) are palmitoylated. Inhibition of palmitic acid incorporation in DAT synaptosomes with 2-bromopalmitate caused a marked inhibition of transport $V_{\max }$ with no losses of DAT protein or changes in DAT surface levels; this indicated a direct effect of the loss of palmitoylation by reducing transport kinetics.

The key experiment for identifying the biological ligand is LC-HRMS analysis of the protein incubated with nerve vesicles with and without MgATP. The resulting LC chromatograms are almost exactly superposable (Figs. $3 b$ and $3 c$ ), with a striking difference in the peak corresponding to palmitic acid, which disappears for the protein incubated with nerve vesicles and MgATP. These results show that WT ReP1-NCXSQ does not bind palmitic acid, but palmitic acid is trapped during the incubation with nerve vesicles. In the presence of MgATP and vesicles the palmitic acid is released, probably to the exchanger. This suggests that palmitic acid may play a crucial role in the activity of ReP1-NCXSQ, but the mechanism of the regulation remains unknown, in particular how MgATP stimulates both lipid release and activation of the $\mathrm{Na}^{+} / \mathrm{Ca}^{2+}$ exchanger. 
In conclusion, the present findings suggest a novel mechanism based on the transport of palmitic acid for fine-tuning of the regulation of NCXSQ1 by ReP1NCXSQ.

This work was supported by grants from the US National Science Foundation (MCB 0444598), Fondo Nacional para Investigaciones Científicas y Tecnológicas (PICT-05-38073) and Consejo Nacional de Investigaciones Científicas Y Técnicas (PIP 2010-2012: GI11220090100063), Argentina, Fondo Nacional para Ciencia y Técnica (S1-9900009046 and G-2001000637) and Fundación Polar, Venezuela. We thank the IGBMC Structural Genomics Platform staff (in particular Pierre Poussin) and l'Établissement Français du Sang-Alsace (in particular Philippe Ohlmann and Christian Gacher). This work was supported by CNRS, INSERM, Université de Strasbourg, Région Alsace and Hôpital Civil de Strasbourg. We also thank Myriam Siravegna and Dr Daniel Raimunda (INIMEC-CONICET) for their helpful expertise. DA was supported by a studentship from the French Ministère de la Recherche. TP was supported by Russian Foundation for Basic Research (grant number RFBR 10-04-00254-a).

\section{References}

Adams, P. D., Grosse-Kunstleve, R. W., Hung, L.-W., Ioerger, T. R., McCoy, A. J., Moriarty, N. W., Read, R. J., Sacchettini, J. C., Sauter, N. K. \& Terwilliger, T. C. (2002). Acta Cryst. D58, 1948-1954.

Beaugé, L., Delgado, D., Rojas, H., Berberián, G. \& DiPolo, R. (1996). Ann. N. Y. Acad. Sci. 779, 208-216.

Berberián, G., Bollo, M., Montich, G., Roberts, G., Degiorgis, J. A., Dipolo, R. \& Beaugé, L. (2009). Biochim. Biophys. Acta, 1788, 1255-1262.

Berberián, G., DiPolo, R. \& Beaugé, L. (2007). Ann. N. Y. Acad. Sci. 1099, 152-165.

Berberián, G., Podjarny, A., DiPolo, R. \& Beaugé, L. (2012). Prog. Biophys. Mol. Biol. 108, 47-63.

Blaustein, M. P. \& Lederer, W. J. (1999). Physiol. Rev. 79, 763-854.

Bourguet, W., Andry, V., Iltis, C., Klaholz, B., Potier, N., Van Dorsselaer, A., Chambon, P., Gronemeyer, H. \& Moras, D. (2000). Protein Expr. Purif. 19, 284-288.

DiPolo, R. \& Beaugé, L. (2002). J. Physiol. 539, 791-803.

DiPolo, R. \& Beaugé, L. (2006). Physiol. Rev. 86, 155-203.

DiPolo, R., Berberián, G., Delgado, D., Rojas, H. \& Beaugé, L. (1997). FEBS Lett. 401, 6-10.

Doering, A. E. \& Lederer, W. J. (1994). J. Physiol. 480, 9-20.

Elviri, L., Zagnoni, I., Careri, M., Cavazzini, D. \& Rossi, G. L. (2001). Rapid Commun. Mass Spectrom. 15, 2186-2192.

Esteves, A. \& Ehrlich, R. (2006). Comp. Biochem. Physiol. C Toxicol. Pharmacol. 142, 262-274.

Folli, C., Ramazzina, I., Percudani, R. \& Berni, R. (2005). Biochim. Biophys. Acta, 1747, 229-237.

Furuhashi, M. \& Hotamisligil, G. S. (2008). Nature Rev. Drug Discov. 7, 489-503.
Gillilan, R. E., Ayers, S. D. \& Noy, N. (2007). J. Mol. Biol. 372, 12461260.

Gu, P.-L., Gunawardene, Y. I. N. S., Chow, B. C. K., He, J. G. \& Chan, S.-M. (2002). Gene, 288, 77-84.

Hilge, M., Aelen, J. \& Vuister, G. W. (2006). Mol. Cell, 22, 15-25.

Hilgemann, D. W., Matsuoka, S., Nagel, G. A. \& Collins, A. (1992). J. Gen. Physiol. 100, 905-932.

Hunter, D. J. B., Macmaster, R., Roszak, A. W., Riboldi-Tunnicliffe, A., Griffiths, I. R. \& Freer, A. A. (2005). Acta Cryst. D61, 10671071.

Jakobsson, E., Alvite, G., Bergfors, T., Esteves, A. \& Kleywegt, G. J. (2003). Biochim. Biophys. Acta, 1649, 40-50.

Kumar, S., Tamura, K. \& Nei, M. (1993). Comput. Appl. Biosci. 10, 189-191.

Larkin, M. A., Blackshields, G., Brown, N. P., Chenna, R., McGettigan, P. A., McWilliam, H., Valentin, F., Wallace, I. M., Wilm, A., Lopez, R., Thompson, J. D., Gibson, T. J. \& Higgins, D. G. (2007). Bioinformatics, 23, 2947-2948.

Marr, E., Tardie, M., Carty, M., Brown Phillips, T., Wang, I.-K., Soeller, W., Qiu, X. \& Karam, G. (2006). Acta Cryst. F62, 10581060.

Molenaar, C. M., Prange, R. \& Gallwitz, D. (1988). EMBO J. 7, 971-976.

Murshudov, G. N., Skubák, P., Lebedev, A. A., Pannu, N. S., Steiner, R. A., Nicholls, R. A., Winn, M. D., Long, F. \& Vagin, A. A. (2011). Acta Cryst. D67, 355-367.

Navaza, J. (1994). Acta Cryst. A50, 157-163.

Nicoll, D. A., Sawaya, M. R., Kwon, S., Cascio, D., Philipson, K. D. \& Abramson, J. (2006). J. Biol. Chem. 281, 21577-21581.

Ono, T. \& Odani, S. (2010). Proc. Jpn Acad. Ser. B Phys. Biol. Sci. 86, 220-228.

Otwinowski, Z. \& Minor, W. (1997). Methods Enzymol. 276, 307-326.

Perrakis, A., Sixma, T. K., Wilson, K. S. \& Lamzin, V. S. (1997). Acta Cryst. D53, 448-455.

Potier, N., Billas, I. M. L., Steinmetz, A., Schaeffer, C., van Dorsselaer, A., Moras, D. \& Renaud, J.-P. (2003). Protein Sci. 12, 725-733.

Pu, J., Peng, G., Li, L., Na, H., Liu, Y. \& Liu, P. (2011). J. Lipid Res. 52, 1319-1327.

Reese-Wagoner, A., Thompson, J. \& Banaszak, L. (1999). Biochim. Biophys. Acta, 1441, 106-116.

Sacchettini, J. C., Gordon, J. I. \& Banaszak, L. J. (1989). J. Mol. Biol. 208, 327-339.

Sacchettini, J. C., Scapin, G., Gopaul, D. \& Gordon, J. I. (1992). J. Biol. Chem. 267, 23534-23545.

Scapin, G., Young, A. C., Kromminga, A., Veerkamp, J. H., Gordon, J. I. \& Sacchettini, J. C. (1993). Mol. Cell. Biochem. 123, 3-13.

Schiøtt, B., Iversen, B. B., Madsen, G. K. H. \& Bruice, T. C. (1998). J. Am. Chem. Soc. 120, 12117-12124.

Tsuchiya, Y., Hatakeyama, H., Emoto, N., Wagatsuma, F., Matsushita, S. \& Kanzaki, M. (2010). J. Biol. Chem. 285, 34371-34381.

Tulloch, L. B., Howie, J., Wypijewski, K. J., Wilson, C. R., Bernard, W. G., Shattock, M. J. \& Fuller, W. (2011). J. Biol. Chem. 286, 36020-36031.

Urquiza, A. M. de, Liu, S., Sjöberg, M., Zetterström, R. H., Griffiths, W., Sjövall, J. \& Perlmann, T. (2000). Science, 290, 2140-2144.

Xu, Z., Bernlohrs, D. \& Banaszak, L. (1993). J. Biol. Chem. 268, 7874 7884.

Zlatanos, S., Laskaridis, K., Feist, C. \& Sagredos, A. (2006). Mol. Nutr. Food Res. 50, 967-970. 